\title{
Reclaiming American Indian Women Leadership: Indigenous Pathway to Leadership
}

\author{
Margo Hill1, Mary Ann Keogh Hoss ${ }^{2 *}$ \\ ${ }^{1}$ Department of Urban Planning, Eastern Washington University, Cheney, Washington, USA \\ ${ }^{2}$ Department of Health Services Administration, Eastern Washington University, Cheney, Washington, USA \\ Email: ^mhoss@ewu.edu
}

How to cite this paper: Hill, M., \& Hoss, M. A. K. (2018). Reclaiming American Indian Women Leadership: Indigenous Pathway to Leadership. Open Journal of Leadership, 7, 225-236.

https://doi.org/10.4236/oj1.2018.73013

Received: August 2, 2018

Accepted: September 26, 2018

Published: September 29, 2018

Copyright $\odot 2018$ by authors and Scientific Research Publishing Inc. This work is licensed under the Creative Commons Attribution International License (CC BY 4.0).

http://creativecommons.org/licenses/by/4.0/

\begin{abstract}
There was no identified leadership model for American Indian women leaders. Through an exhaustive review of leadership styles it was identified that the Centered Leadership approach lends itself to the culture of American Indian Women. The components of the Centered Leadership approach include: utilizing personal strengths, managing energy, positive framing, relationship building, and collaborating with others to take advantage of opportunities. Based on the review of the literature and native women's leadership styles, the concepts of the Centered Leadership Model were utilized to develop "Native Women Leadership: Indigenous Pathway". Prior to European contact, native women held positions of leadership, shared in decision making and owned property. Today Native women leaders and managers are reclaiming their decision making authority to improve the lives of their nations. The Native Women Indigenous Pathway has not come without barriers and discrimination. The Centered Leadership approach assists in the examination of the American Indian woman's pathway to decision making. Native women find themselves living in two worlds and must navigate expectations and responsibilities by switching between mainstream American and tribal values. How a native woman decides to negotiate these two worldviews is part of what creates her individual identity and her leadership style. A Native American Leadership Indigenous Pathway model is proposed.
\end{abstract}

\section{Keywords}

Authenticity, Leadership Education, Personal Development, Training and Development, American Indian Women, Native Women, Leadership, Indigenous Pathway, Centered Leadership 


\section{Introduction}

American Indian women are reclaiming their roles as leaders in tribal communities. Historically, American Indian women exercised a significant amount of sociopolitical power within tribal nations. Today, contemporary American Indian women are seeking to regain this prominence (Portman \& Herring, 2001; Tsosie, 1988) and are establishing themselves as leaders. The role of Indian women in tribal decision making was deeply eroded by European contact (Jaimes \& Halsey, 1992). Native women, who have earned their education and found their pathways to opportunity, have demonstrated their competence as managers and leaders of their organizations. Although Native American tribes share many values and world views in contrast to Anglo culture, there are many distinct tribal nations and differences among them. Across the United State there are 567 federally recognized tribes with many different cultural views (Indian Entities Recognized and Eligible to Receive Services from the United States Bureau of Indian Affairs, 2017).

\section{Historical Context-Federal Indian Policies and Colonialism}

Power relation between men and women in tribal communities in pre-colonial times is one of interdependence. A review of the literature finds that leadership from an American Indian perspective is seen as shared vision and responsibility. "Today American Indian governance is filled not with the romantic notion of male 'chiefs' as wise, supreme, all-knowing grandfathers but with tribal councils or executive committees consisting of both male and female leaders who are holding positions of leadership" (Portman \& Garret, 2005: p. 284). American Indian tribes are exercising their tribal sovereignty and working to improve the lives of their citizens. American Indian women have consistently served in leadership capacities throughout indigenous history.

There are many social roles defined by gender but it is clear that women were integral to decision making of tribal communities. The literature describes the role of Native American women as more powerful than European men would have understood. Although the social organization and decision making process is different for every tribe, it is clear that women held decision making authority. For example, Iroquois women were reported to have owned farming land and residences, nominated chiefs, and participated in tribal decision-making (Bilharz, 1995). American Indian women were not limited to management of the home and the harvesting of foods.

Osburn (1998) found, in the Ute society, prior to the patriarchal social structure imposed by the U.S. government with the reservation system, that women "participated in councils, were active in warfare and provided leadership and power in spiritual matters" (p. 23). In the spring of 1858 Brigadier General Hylan B. Lyon witnessed and wrote of a Spokane Indian woman that accompanied the War Chief Qualchan. He noted that she rode alongside Qualchan and on a 
fine Indian Horse and carried a long staff (Coffman, 1959).

Muller (1998) states that there are several compelling and well-documented case studies that illustrate the unwillingness of the colonists to deal with matriarchal forms of governance and women leaders of the tribes. For example, the colonists convinced the Cherokee men that women ought not to comprise their government council and the constitution was changed to prevent women from serving as council members. This led to the diminution of the value of native women's leadership roles (Allen, 1992).

For certain Pueblo communities in New Mexico, women are denied leadership positions. Prindeville \& Gomez (1999) articulated that this exclusion likely had its foundation in "traditional" religious beliefs, and is likely the "byproduct of the legacy of patriarchal colonialism and Christianity and demonstrates that the understanding of historical context complicates their findings." (p. 19).

American Indians, to a greater degree than many other groups, were subjected to "cultural assaults" (Zinn \& Dill, 1994: p. 7) by Europeans who sought to "civilize" or exterminate them. Tribal people were often subjected to Christian boarding schools that removed them from their families and tribal culture. They were beaten for speaking their tribal languages and practicing tribal customs. Many young Native American children were subjected to abuse and died at boarding schools (Jaimes \& Halsey, 1992). The resulting historical trauma speaks to the resiliency of native people and what they must overcome to be successful.

Rations, reservations, and relocations acted as agents of assimilation, marking U.S.-Indian relations for more than 200 years (Young, n.d.). In early European contact and into the 1970's, the only jobs available for women were waitresses, hotel maids and doing the laundry. These menial employment positions were in stark contrast to the influence and decision making authority traditionally held by native women in their tribal communities.

A review of the literature on American Indian Women and American Indian women writers argue that the subordinate status of contemporary tribal women results from the imposition of Spanish and Anglo Colonists' policies, programs, and gender-role stereotypes, and not from pre-colonial tribal gender roles (Muller, 1998). Federal Indian law and United States government policies obliterated the legal standing of Native American women. The Dawes Act, also known as the Allotment Act, gave tracts of land out to male heads of household, further eroding if not completely extinguishing Native American women's roles. Although some tribal women did receive allotments they primarily went to male heads of households (Lajimodiere, 2011). "On Navajo lands, the U.S. government refused to recognize land ownership patterns that accorded such right to women; it allotted reservation lands to Navajo men and listed men as head of household. This totally ignored the Navajo clan relationship that is based on matrilineal principles" (Muller, 1998: p. 17).

In many tribes, Native American women had spiritual, political, and economic power, not more than men, but at least equal to men. Lajimodiere (2011) noted that "the passage of the Indian Reorganization Act (IRA) imposed an 
elected tribal council format that was based on Eurocentric governmental model, and traditional ways of selecting leaders were wiped out" (p. 59). Many tribes in the Pacific Northwest are organized under the Indian Reorganization Act and have adopted the IRA model constitutions that delineate tribal elections. The recognition of the tribal right to self-government was not complete, however; the constitutions and by-laws were subject to approval of the Secretary of the Interior (Canby, 2004). At the Spokane Tribe, under this IRA modeled constitution only one tribal female had been elected to tribal council in 70 years. At that same time, the Spokane reservation's Indian Health Service Unit Director, the Bureau of Indian Affairs (BIA) Superintendent, the Chief Financial Officer of the tribe and the Tribal Attorney were all females.

\section{Indigenous Pathway to Leadership}

There is no direct pathway to leadership for native women in tribal communities. Native Women leaders come to their positions through their own personal journey, as well as their cultural, educational, professional, and relational experiences. The opportunities that are offered in their reservation communities are very different from those found in the urban environment. Native women often have to find their way to their own spiritual, cultural, educational and professional pathways.

As illustrated in the Native Women Leadership Indigenous Pathway model, many native women experience a number of barriers to their success: racism and discrimination, lack of financial resources (for education), and negative tribal politics (Figure 2). Also, Lajimodiere (2011) found that native participants in her study experienced jealousy, gossiping, backbiting, and sabotaging from other female peers and supervisees. This phenomenon is also known as horizontal or lateral violence.

\section{Personal Identity-Purpose and Balance}

In examining contemporary Native American women leaders one must understand how they develop positive cultural and gender identities. Identity is defined by native women describing themselves, describing the significant events or turning points in their life, and what influenced their life choices. A common theme throughout the literature is that Native women acknowledge that a strong cultural identity is central to their educational career aspirations and success. Cultural identity is the connectedness that native women have to their tribal community, the connections to their ancestors through land and through ceremonies. Part of native woman's identity comes from her cultural teachings from her grandmother. Many native women's grandmothers and great-grandmothers told stories and sang songs to teach their granddaughters the values and beliefs of the tribe.

Often their pathway is forged by their passionate commitment to improving the lives of tribal people and conditions for their tribal communities. Native 
women often find their identity in a strong sense of duty to their tribal community. This sense of duty comes from being responsible and knowing what needs to be done and getting things done. In the Spokane Tribal language they often call people who get things done "cee ceuse" which means "smart." However, it means more than just "smart or intelligence" it means "to be capable." Tribal community's value people who get things done and they are recognized as being capable and connote that as intelligence.

Native women have to balance their college education with their active participation in tribal issues and their families. Often time native women are challenging the status quo by leaving the reservation and obtaining a college degree. In fact, many native women are directed to vocational schools by school counselors.

\section{Spirituality}

Native spirituality is described as being part of something greater than oneself that gives purpose and meaning to life. "Each woman expressed her spirituality in a highly personal and individualized way and spoke of it as a journey" (Barkdull, 2009: pp. 128-129). Often native women incorporate elements of the Christian faith into their spiritual practices as well as their tribal traditional spiritual beliefs and practices that were handed down through their own families. Prayer is a powerful element of traditional tribal practices in daily life. Tribal people offer prayer and prayer songs that call the salmon home for spawning. The grandmothers offer prayer and thankfulness before they dig camas and roots or pick huckleberries. Men say a prayer of thanksgiving after taking the life of an elk or deer. Tribal leaders today offer prayer before they begin their council meetings.

Tribal people who were sent to religious boarding schools may say they were "raised Catholic" or that they are "Presbyterians". They may have a sense of loyalty to their Christian religion if it was taught to them by their family elders. Native tribal religions do not have institutional structures comparable to Christian churches (Lajimodiere, 2011). Lajimodiere interviewed a tribal college administrator who said "I was brought up a Catholic, I attend sweats, sun dance. The creator knew I would walk both worlds ... to be exposed to both and see the goodness in both" (p. 69). Native women work to find a balance between the Western way of thinking and their own tribal traditional values.

As Barkdull (2009) explained "A deep regard for the spiritual dimension of life, the integration of spirituality into everyday activities, and the valuing of harmony and balance were sources of sustenance for the women as they navigated personal, career, and political challenges." (p. 133).

\section{Living in Two Worlds}

In reviewing the literature, there is a recurring theme that native women are living in two worlds. American Indian writers describe an experience of indigenous people surviving within a colonized state or of negotiating the native and Anglo cultures (Muller, 1998; Crozier-Hogle, Wilson, Leibold, Saitta, \& Sarris, 1997; 
Harjo \& Bird, 1998; Pelly, 1991).

Native women are conscious of having to navigate the cultural and social environments of both their tribal culture and that of the "Anglo" world or mainstream culture. Many tribes place value on obtaining an education so that they can have success in mainstream culture. Tribal females do not have to sacrifice their indigenous cultural practices in order to find success and defined by a European dominant society.

One major consideration is the tribal organizational framework of working together in cooperation versus one of competition. As Portman and Garrett (2005) state, "American Indian women are extensions of their tribal nationsocially, emotionally, historically, and politically" (p. 287). For many American Indians our cultural identity is based on our tribal membership, extended family and community. "The tribe is an interdependent system of people who perceive themselves as parts of the greater whole rather than a whole consisting of individual parts" (Garrett \& Garrett, 2003: p. 1).

Native women find their pathway to leadership with two different worldviews. "Traditional American Indian people judge themselves and their actions according to whether or not they are benefiting the tribal community and its continued harmonious functioning. In American mainstream society, worth and status appear to be based on occupation or achievements" (Garrett \& Garrett, 2003: p. 287). Although native women work to advance in their careers, individual achievement is not their primary focus. They are often promoted when they are working hard to achieve projects for betterment of their tribal communities.

Native women must be able to work in two worlds with different expectations. "In order to negotiate the world of work, the women adopted behaviors and acquired skills that are substantially different from those cultivated by the tribal cultures in which they grew up" (Mueller, 1998: p. 11). Some native women are taught to be reserved in their culture and not to speak up. Other native women come from generations of strong Indian women that served as interpreters for chiefs or advised tribal councils.

The contrasting worldview of Anglo dominant society is a linear orientation to problem solving that proceeds in a straight line as the most efficient way to get from one place to another. As Mueller (1998) notes "Anglo linear orientation to time is represented by planning" and "this is not a feature of traditional tribal culture, yet the women managers must continually plan activities in all of their jobs" (p. 13). Anglo organizational structures have been imposed on tribal communities. Tribal governments and tribal enterprises have adopted Anglo organizational charts and work norms of mainstream America. Some mainstream American values like assertiveness and competition clash with traditional tribal culture. However, many tribal traditions continue alongside Anglo work norms. The previous description of tribal council leaders beginning meetings with a prayer of thanksgiving and of guidance and direction for decisions made and work that will be done is an example of this. 
Native women living in two worlds can choose personal values from both worlds and define themselves through experiences from their tribal community and the dominant culture. How a native woman decides to negotiate these two worldviews is part of what creates her individual identity and leadership style.

\section{Power and Authority}

American Indian women are effective in getting things done. In a study completed by Taylor and Strauss (2006), the indigenous human service leaders described their style as "democratic and collaborative" (p. 143) and occasionally expressed discomfort with the notion of leadership itself, which they view more as "circular" (pp. 131-132). Native women leaders would describe their leadership style as more consultative and participatory then holding power and authority in their own position. Moreover, Taylor and Strauss (2006) found that participants in their study "downplayed the use of power and control in describing their role as a leader and described their leadership style as sharing, building, collaborative, and mentoring process" (p. 143).

Muller (1998) interviewed a female who held a senior-level position in Navajo government. She discussed tribal decision-making patterns. She explained that the Navajo value system is a big factor in the decision making process. It may be asked "Have you consulted with any of the elders before you're making this recommendation?" (p. 10). This is one more example how tribal decision making is different from mainstream America or corporate decision making. Some tribal general council meetings go for days and may go late into the evening if the tribe is deciding something important for the future of the tribe.

\section{Passing on Cultural Knowledge}

Native women also actively lead by being involved in passing on their tribe's culture, stories, ceremonies, and traditions to a new generation. In tribal communities, entering the tribal dance circle is an important example of how a tribe's cultural knowledge is passed onto the next generation. Usually as an infant in the arms of a loving relative a baby will be brought into the circle. The grandmother or mother will make their little one's regalia and as they grow, he or she is taught to dance beside the family member in the circle. Later, as the child learns the expectation of the circle and has respect for the dance arena, he or she will dance independently from the adult but as part of the tribal community. Then will lead others to the dance circle.

It is also important for native female leaders to mentor other native women. Keating (2002) asserts that there is evidence to support the power of women mentoring women. It creates a "relational context" (p. 28) that is conducive to development and expansion of career skills, salary and professional satisfaction. Native women help others in their tribal community and circles to find their gifts.

\section{Identifying American Indian Women's Style}

The literature identifies a number of traits that American Indian women exhibit 
and articulate in leadership roles both within the tribe and in the outside work world. Prior to European influence as discussed earlier, American Indian women "attained a high or equal complementary status with men" (Muller, 1998: p. 12). Portman and Garrett (2005) identify the values of shared vision, responsibility and nurturing/mentoring influence. Further leadership skills identified are patience, listening, contemplating the situation, and innovative strategies. Portman and Garrett (2005) go on to identify collaboration, compassion and courage as a "central value among American Indian traditionalists" (p. 288). Barkdull (2009) discusses the themes of spirituality, Indianness and reciprocity/inclusiveness. Muller (1998) discusses that fact that American Indian women are not raised to be assertive and competitive. American Indian women leaders have identified traits such as statesmanship, humility, grace, determination and decisiveness. Goh Yuan Sheng and Soutar (2005) state "leadership style is significantly influenced by the leader's immediate and extended family, clan or tribe" (p. 24). Nan (2014) discusses leadership as largely culturally oriented, embracing traditional beliefs, norms and values.

In 2008, a new approach to leadership was introduced. It is Centered Leadership. This leadership style consists of five broad and interrelated dimensions (Barsh, Cranston, \& Craske, 2008). This model was developed by interviewing female leaders across the globe to identify the traits that characterized them. Findings suggest that "meaning in one's activities has the strongest impact on general satisfaction with one's life" (Barsh, Mogelof, \& Webb, 2010: p. 2). These dimensions are defined below:

- Meaning or finding your strengths and putting them to work in the service of inspiring purpose

- Managing energy or knowing where your energy comes from, where it goes and what you can do to manage it

- Positive framing or adopting a more constructive way to view your world, expand your horizons, and gain the resilience to move ahead even when bad things happen

- Connecting or identifying who can help you grow, building stronger relationships, and increasing your sense of belonging

- Engaging or finding your voice, becoming self-reliant and confident by accepting opportunities and the inherent risks they bring and collaborating with others (Barsh et al., 2008: p. 2).

The coming together of "physical, intellectual, emotional and spiritual strength that drives personal achievement and in turn inspires others to follow" (Barsh et al., 2008: p. 3) describes the concepts presented previously.

This style shares many traits previously identified for American Indian Women. Among these are relationship building, inclusiveness, and collaboration. With the style identified, a shared vision is stated or implied. The centered leadership provides a most encompassing approach. The model is presented on the next page (Figure 1). 


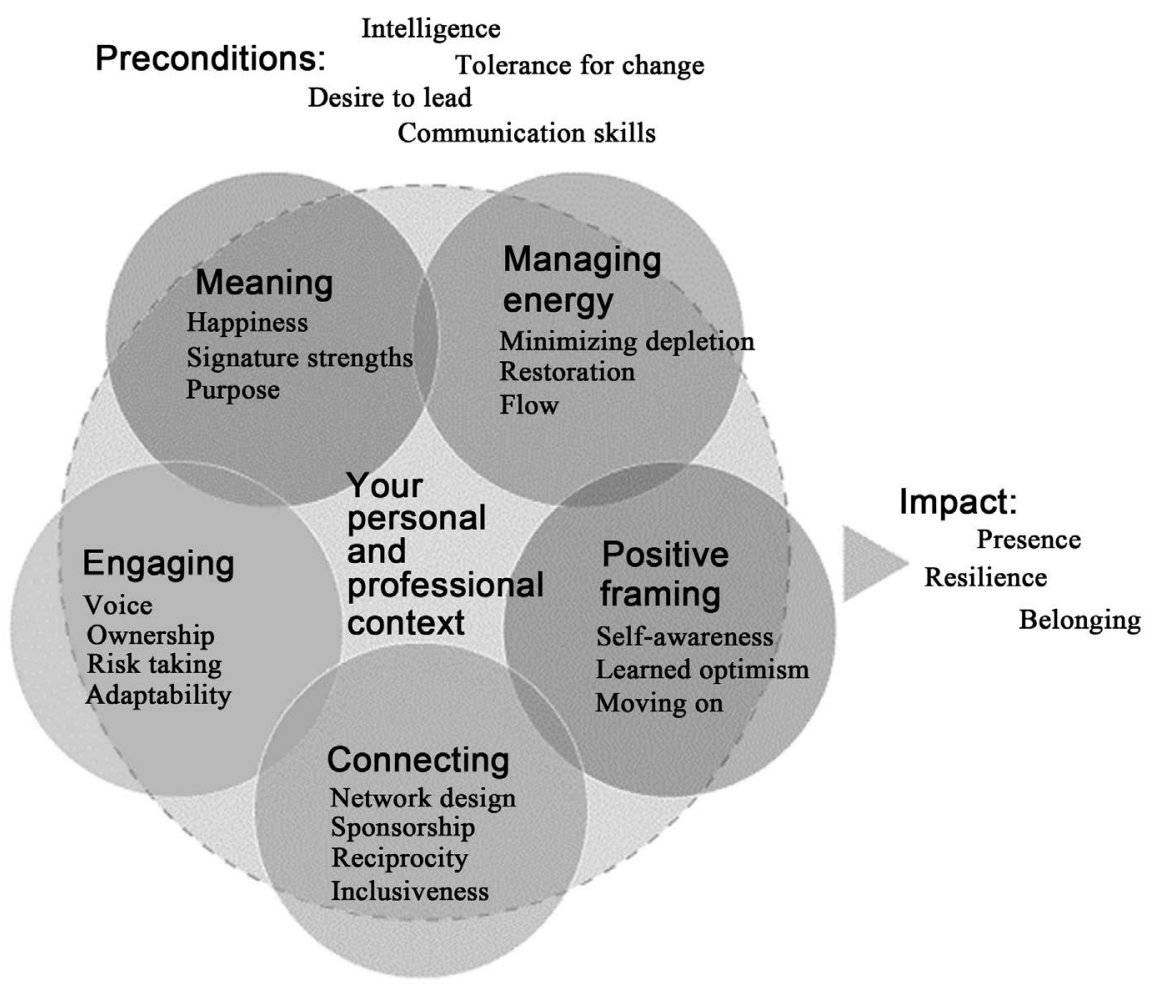

Figure 1. The centered leadership model.

This model has been used as a foundation for development of the Native Women Leadership Indigenous Pathway that specifically outlines concepts introduced in this paper (Figure 2). This pathway graphically depicts the coming together of the individual identity, the Clan/Tribal Cultural expectations (language \& belonging), and the family responsibilities. It also identifies common barriers and common leadership skills found in native women. As noted in the literature, indigenous women view leadership as more "circular". Their leadership style is democratic and collaborative. One Comanche leader commented "It's more circular. Not a pyramid. It takes all of us to make it work" (Taylor \& Stauss, 2006: p. 132). This pathway was created by M. Hill (2017), a Spokane Tribal citizen. It is hoped that this pathway captures elements that drive Native American women on their path to leadership roles.

\section{Conclusion}

The role of Native American Women as defined demonstrates that motivation for Indian women leaders is based on their cultural values. They have a strong desire to make things better for the next generation. Native women leaders work to find a balance between the calling to serve their people and the needs of their families and personal lives. Although the opportunities for leadership was thwarted by Euro-centric attitudes and U.S. Federal Indian policies provided further barriers, Native Women continue to successfully find their pathway to leadership to serve as Tribal Council women and managers in tribal organizations. Native women with their unique leadership skills continue to work to 


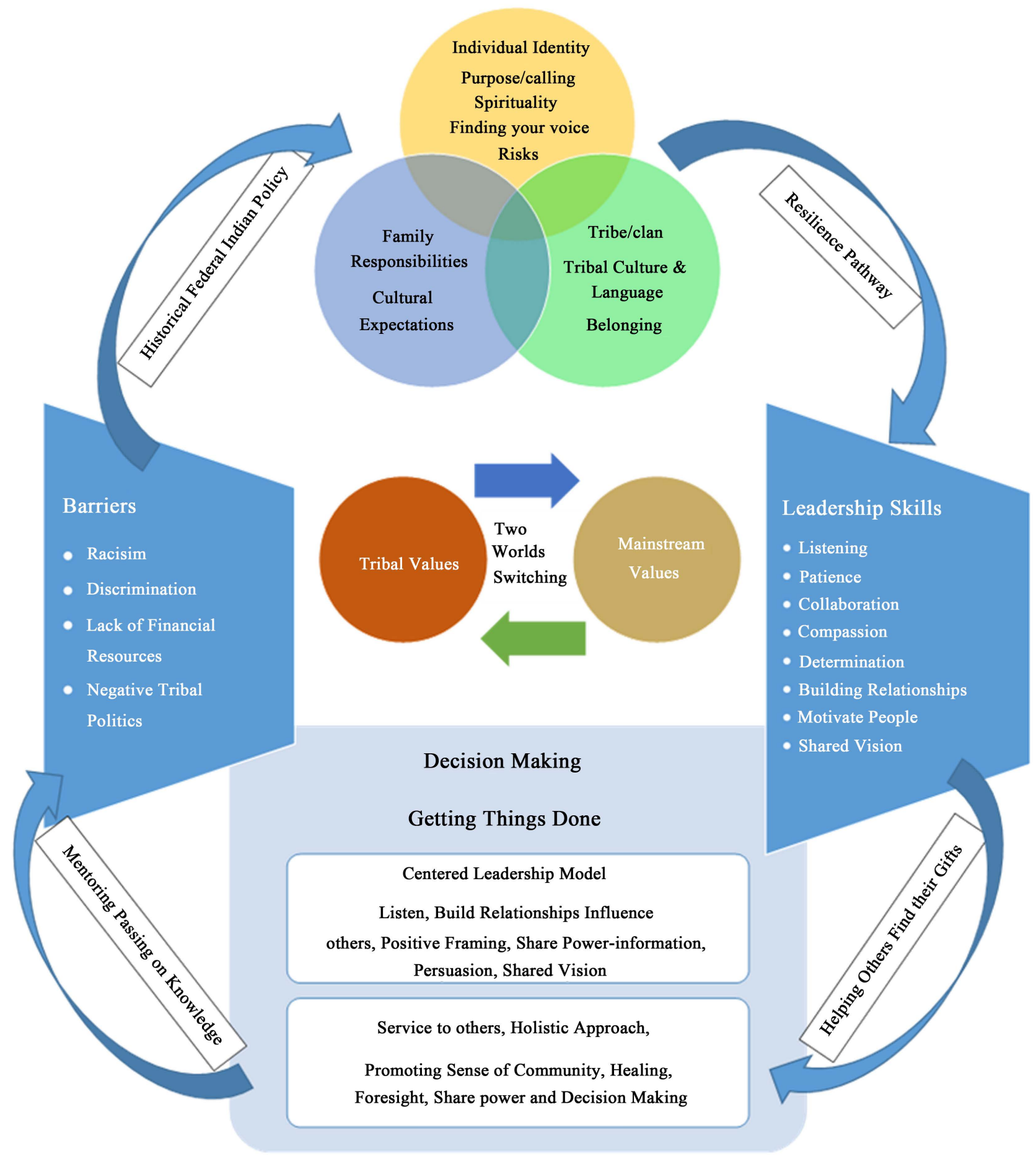

Figure 2. Native women leadership indigenous pathway, developed by margo hill, 2018. Copyright pending. (@ 2017 Margo Hill, J.D.)

improve the lives of their citizens. They continue to find a balance between two world views, meet their professional obligations, and honor their traditional tribal cultural expectations.

The Native Women Leadership Indigenous Pathway is a beginning step in defining a model that could be used. This model would be useful for those mentoring 
American Indian women. It may also be valuable in the training and education of American Indian women for leadership roles in both of the worlds they navigate. The next step in the process is to implement use of the Pathway and monitor outcomes.

\section{Conflicts of Interest}

The authors note there is no conflict of interest.

\section{References}

Allen, P. G. (1992). The Sacred Hoop: Recovering the Feminine in American Indian Traditions. Boston, MA: Beacon Press.

Barkdull, C. (2009). Exploring Intersections of Identity with Native American Women Leaders. Journal of Women and Social Work, 24, 128-133. https://doi.org/10.1177/0886109909331700

Barsh, J., \& Lavoie, J. (2014). Centered Leadership: Leading with Purpose, Clarity, and Impact. New York: Crown Business.

Barsh, J., Cranston, S., \& Craske, R. A. (2008). Centered Leadership: How Talented Women Thrive. McKinsey Quarterly.

https://www.mckinsey.com/global-themes/leadership/centered-leadership-how-talente d-women-thrive

Barsh, J., Mogelof, J., \& Webb, C. (2010). The Value of Centered Leadership: McKinsey Global Survey Results. McKinsey \& Company.

http://www.joannabarshbook.com/wp-content/uploads/2014/04/2010.-The-Value-of-C entered-Leadership.pdf

Bilharz, J. (1995). First among Equals? The Changing Status of Seneca Women. In L. F. Klein, \& L. A. Ackerman (Eds.), Women and Power in Native North America (pp. 101-112). Norman, OK: University of Oklahoma Press.

Canby, W. C. (2004). Indian Reorganization and Preservation of the Tribes: 1934 to 1953. In American Indian Law in a Nutshell (p. 25). St. Paul, MN: West Publishing.

Coffman, E. M. (1959). Memoirs of Hylan B. Lyon Brigadier General, C.S.A. Tennessee Historical Quarterly, 18, 35-53. http://www.jstor.org/stable/42621748

Crozier-Hogle, L., Wilson, D. B., Leibold, J., Saitta, G., \& Sarris, G. (1997). Surviving in Two Worlds: Contemporary Native American Voices. Austin, TX: University of Texas Press.

Garrett, M., \& Garrett, J. T. (2003). Native American Faith in America. New York: Shoreline Publishing Group LLC.

Goh Yuan Sheng, V., \& Soutar, G. N. (2005). The Role of Ethical Behaviours in the Relations between Leadership Styles and Job Performance. ANZMAC 20015 Conference: Corporate Responsibility (p. 24).

https://www.researchgate.net/profile/Geoffrey_Soutar/publication/265806307_The_Role_ Of_Ethical_Behaviours_In_The_Relations_Between_Leadership_Styles_And_Job_Perfor mance/links/54bcdd310cf24e50e9409dee/The-Role-Of-Ethical-Behaviours-In-The-Rela tions-Between-Leadership-Styles-And-Job-Performance.pdf

Harjo, J., \& Bird, G. (1998). Reinventing the Enemy's language: Contemporary Native Women's writings of North America. New York: W. W. Norton \& Company.

Hill, M. (2017). Native Women Leadership Indigenous Pathway. Unpublished Raw Data. 
Indian Entities Recognized and Eligible to Receive Services from the United States Bureau of Indian Affairs, 82 Fed. Reg. 4915 (2017).

Jaimes, M. A., \& Halsey, T. (1992). American Indian Women at the Center of Indigenous Resistance in North America. In M. A. Jaimes (Ed.), The State of Native America: Genocide, Colonization, and Resistance (pp. 311-344). Boston, MA: South End Press.

Keating, L. (2002). Women Mentoring Women: The Rewards of Giving. Women in Business, 54, 28.

Lajimodiere, D. K. (2011). Ogimah Ikwe: Native Women and Their Path to Leadership. Wicazo Sa Review, 26, 57-82. https://doi.org/10.1353/wic.2011.0011

Muller, H. J. (1998). American Indian Women Managers: Living in Two Worlds. Journal of Management Inquiry, 7, 4-28. https://doi.org/10.1177/105649269871002

Osburn, K. M. B. (1998). Southern Ute Women: Autonomy and Assimilation on the Reservation, 1887-1934. Albuquerque, NM: University of New Mexico Press.

Pelly, D. F. (1991). Pond Inlet: An Inuit Community Caught between Two Worlds. Canadian Geographic, 111, 46-52.

Portman, T. A. A., \& Garrett, M. T. (2005). Beloved Women: Nurturing the Sacred Fire of Leadership from an American Indian Perspective. Journal of Counseling \& Development, 83, 284-291. https://doi.org/10.1002/j.1556-6678.2005.tb00345.x

Portman, T. A. A., \& Herring, R. D. (2001). Debunking the Pocahontas Paradox: The Need for a Humanistic Perspective. The Journal of Humanistic Counseling, Education and Development, 40, 185-199.

Prindeville, D. M., \& Gomez, T. B. (1999). American Indian Women Leaders, Public Policy, and the Importance of Gender and Ethnic Identity. Journal of Women and Politics, 20, 17-32. https://doi.org/10.1300/J014v20n02_02

Taylor, M. J., \& Stauss, K. (2006). Native American Women Who Lead Human Service Organizations. Journal of Ethnic \& Cultural Diversity in Social Work, 15, 123-146. https://doi.org/10.1300/J051v15n01_06

Tsosie, R. (1988). Changing Women: The Cross-Currents of American Indian Feminine Identity. American Indian Culture and Research Journal, 12, 1-37. https://doi.org/10.17953/aicr.12.1.3723328898018383

Young, M. (n.d.). Native Women Move to the Front of Tribal Leadership. Native Daughters.

http://cojmc.unl.edu/nativedaughters/leaders/native-women-move-to-the-front-of-trib al-leadership

Zinn, M. B., \& Dill, B. T. (1994). Women of Color in U.S. Society. Philadelphia, PA: Temple University Press. 